\title{
AN EFFICIENT CONTACT MODEL FOR DYNAMIC INTERACTION ANALYSIS OF HIGH-SPEED TRAIN AND RAILWAY STRUCTURE INCLUDING DERAILMENT DURING AN EARTHQUAKE
}

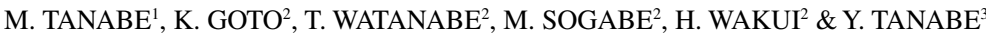 \\ ${ }^{1}$ Kanagawa Institute of Technology, Japan. \\ ${ }^{2}$ Railway Technical Research Institute, Japan. \\ ${ }^{3}$ Laboratory for Computational Mechanics Inc., Japan.
}

\begin{abstract}
A computational model to solve for the dynamic interaction of a high-speed train and railway structure including derailment during an earthquake is given. An efficient mechanical model to express contactimpact behaviours between wheel and rail before derailment, between wheel and the track structure after derailment, and between the car body and railway structure during and after derailment is presented. The motion of the train with nonlinear springs and dampers is modelled in multibody dynamics. The railway structure is modelled with various finite elements. The combined dynamic response of the train and railway structure during an earthquake is obtained by solving the nonlinear equations of motions of the train and railway structure in the modal coordinates subjected to the interaction between the train and railway structure. Numerical examples of a high-speed train running on the railway structure after derailment during an earthquake are demonstrated.

Keywords: contact, derailment, dynamic interaction, FEM, multibody dynamics, post derailment, railway structure, train.
\end{abstract}

\section{INTRODUCTION}

When a high-speed train runs on the railway structure during an earthquake, there is a radical dynamic interaction between the train and railway structure. The huge impact force between the wheel and rail may cause lifting of the wheel, derailment and post-derailment behaviours such as the contact of wheel on the track structure, and also the contact of the car body of the train on the railway structure. It is very important to solve the dynamic interaction between the train and the railway structure including derailment and post-derailment behaviours to build an earthquake-safe railway system.

Regarding the wheel-rail contact, Pombo et al. [1] presented a generic contact detection formulation that allows the lead and lag flange contact in the rail direction. Ju [2] studied the method to express the vertical stiffness between the wheel and rail as a power function of changing contact force and developed a nonlinear moving wheel element to solve the contact problem of a moving train. Montenegro et al. [3] presented an algorithm to express the nonlinear vehicle-structure interaction by constraint equations and to solve them by Lagrange multipliers based on the Newton method due to the nonlinearity.

Regarding the derailment behaviour in the dynamic interaction between the train and the railway structure during an earthquake, Xiao et al. [4] studied the derailment criteria based on

This paper is part of the proceedings of the 15th International Conference on Railway

Engineering Design and Operation (COMPRAIL)

www.witconferences.com 
the derailment coefficient that is defined as the ratio of the lateral force to the vertical force of wheel to predict the derailment and evaluate the vehicle running safety for the various operation speeds of the train and earthquake motions. Sumami et al. [5] studied the way to solve the impact behaviour between the derailed wheel and sleeper based on a wheel-sleeper impact model and investigated the derailed vehicle motion.

However, very little work related to the computational method to solve the dynaimic interaction including derailment and post-derailment behaviours during an earthquake has been reported so far.

In this article, a computational model to solve for the dynamic interaction of a high-speed train and railway structure including derailment and post-derailment during an earthquake is given. An efficient mechanical model to express contact-impact behaviours between wheel and rail before derailment, between wheel and railway structure after derailment and between the car body of the train and railway structure during and after derailment is presented.

The motion of the train with nonlinear springs and dampers is modelled in multibody dynamics. The railway structure is modelled with various finite elements. The modal reduction is applied to equations of motion of the train and railway structure. The combined dynamic response of the train and railway structure during an earthquake is obtained by solving nonlinear equations of motions of the train and railway structure in the modal coordinates subjected to the interaction between wheel and rail before derailment and between the train and railway structure during and after derailment.

Numerical examples of a high-speed train running at high speed on the railway structure after derailment during an earthquake are demonstrated.

\section{MECHANICAL MODEL OF A HIGH-SPEED TRAIN AND RAILWAY STRUCTURE}

\subsection{Mechanical model of a Shinkansen train}

A Shinkansen train (high-speed train in Japan) is modelled in multibody dynamics with rigid components of car body, truck and wheel-set connected by nonlinear springs and dampers as shown in Fig. 1. Assuming that the train runs at a constant speed, the equation of 3D motion of the train with $n$ cars connected is derived with $31 n$ degrees of freedom and written in a familiar matrix form as [6]

$$
M^{V} \ddot{X}^{V}+D^{V}\left(\dot{X}^{V}\right)+K^{V}\left(X^{V}\right)=F^{V}
$$

where $X$ and $F^{V}$ are displacement and load vectors of the train, $M^{V}$ is the mass matrix, and $D^{V}\left(\dot{X}^{V}\right)$ and $K^{V}\left(X^{V}\right)$ are the damping and internal force vectors that are nonlinear depending on the velocity and displacement vectors of the train and railway structure.

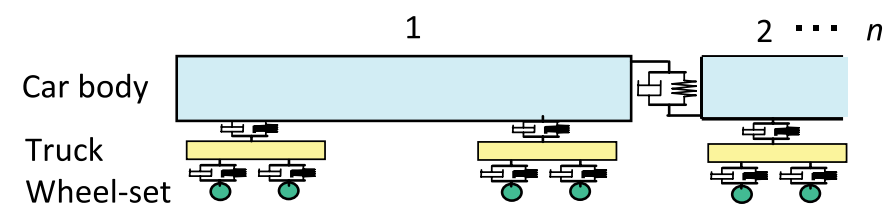

Figure 1: Mechanical model of a Shinkansen train. 


\subsection{Mechanical model of a railway structure}

A railway structure is modelled with various finite elements such as truss, beam, shell, solid, mass and damper elements, and also nonlinear spring element that is to model simply a concrete structure with an elastic-plastic behaviour appeared under cyclic loads during an earthquake [6]. The whole equation of motion of a railway structure is written in the same matrix form as the train as

$$
M^{b} \ddot{X}^{b}+D^{b}\left(\dot{X}^{b}\right)+K^{b}\left(X^{b}\right)=F^{b}
$$

where $X^{b}$ and $F^{b}$ are displacement and load vectors of the railway structure, $M^{b}$ is the mass matrix, and $D^{b}\left(\dot{X}^{b}\right)$ and $K^{b}\left(X^{b}\right)$ are the damping and internal force vectors that are nonlinear depending on the velocity and displacement vectors of the train and railway structure, respectively.

\section{INTERACTION BETWEEN WHEEL AND TRACK STRUCTURE}

\subsection{Contact between wheel and rail before derailment}

Assuming that the yawing and rolling of the wheel-set are relatively small for the contact behaviour between wheel and rail before derailment, two-dimensional geometries of the cross-sections of wheel and rail are considered, and the contact-impact behaviour in the normal direction on the contact surface between wheel and rail is modelled simply in two modes of the contact in the vertical and transverse directions and also in the combination as shown in Fig. 2 [6].

Of the vertical mode of the contact, the contact displacement between wheel and rail in the vertical direction, $\delta_{Z}$, is expressed here as a function of displacements of rail, $\mathrm{z}_{\mathrm{R}}$, and wheel, $\mathrm{z}_{\mathrm{w}}$, in the vertical direction, the relative displacement on the contact surface between wheel and rail in the transverse direction, $d_{y}$, and also rail irregularity in the vertical direction, $\varepsilon_{z}$, as follows [6,7]:

$$
\delta_{Z}=\delta_{Z}\left(z_{R}, z_{W}, d_{y}, \varepsilon_{z}\right)
$$

The contact displacement, $\delta$, in the normal direction on the contact surface between wheel and rail is obtained from the contact angle at the contact position. The contact force on the contact surface between wheel and rail in the normal direction, $H$, is expressed as a function of $\delta$ and $d_{y}$ as follows:

(a)

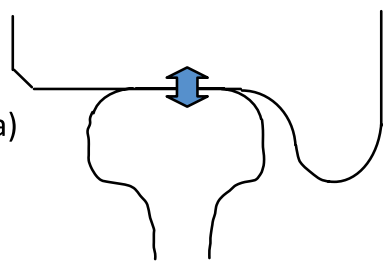

(b)

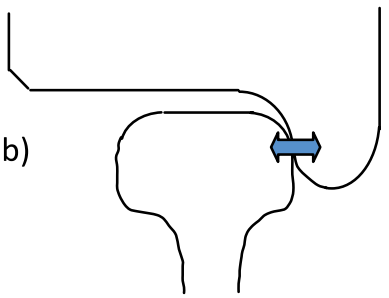

Figure 2: Contact modes between wheel and rail. (a) Vertical direction. (b) Transverse direction. 


$$
H=H\left(\delta, d_{y}\right)
$$

Of the transverse mode of the contact between wheel and rail, the contact displacement in the transverse direction, $\delta_{y}$, is also expressed as a function of $d_{y}, \delta_{Z}$, and the rail irregularity in the transverse direction, $\varepsilon_{y}$, as

$$
\delta_{y}=\delta_{y}\left(d_{y}, \delta_{Z}, \varepsilon_{y}\right)
$$

The contact force is obtained in the same manner as the contact mode in the vertical direction described above.

Regarding the tangential and longitudinal directions on the contact surface between wheel and rail, constitutive equations to describe the relationship between creep forces and slipping rates of wheel are given [8]. The creep force in the tangential direction, $Q_{c}$, and yaw moment, $T_{c}$, due to the creep force in the longitudinal direction on the contact surface between wheel and rail are described mathematically here as functions of slipping rates of wheel in the longitudinal and tangential directions, $S_{x}$ and $S_{t}$, and also of the spin rate around the normal vector on the contact surface, $S_{n}$, as [9]

$$
\begin{gathered}
Q_{c}=Q_{c}\left(S_{x}, S_{t}, S_{n}\right) \\
T_{c}=T_{c}\left(S_{x}\right)
\end{gathered}
$$

\subsection{Derailment criterion}

When the relative displacement between wheel and rail in the transverse direction, $d_{y}$, exceeds derailment criteria, $u_{F}$, in the field side and, $u_{G}$, in the gauge side, as shown in Fig. 3, derailments in the field and gauge sides are initiated, respectively. After the derailment of the wheel from rail during an earthquake, the wheel touches down on the track structure and the postderailment behaviour of the wheel on the track structure starts.

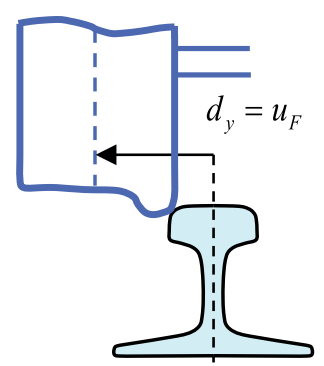

(a)

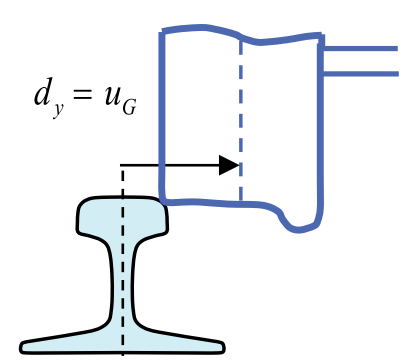

(b)

Figure 3: Derailment criterion of left wheel. (a) Field-side derailment. (b) Gauge-side derailment. 


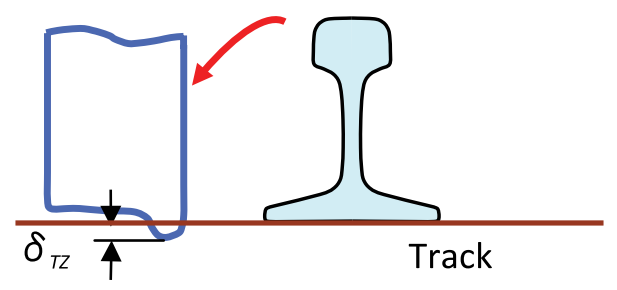

Figure 4: Vertical relative displacement between wheel and track structure, $\delta_{\mathrm{TZ}}$.

3.3 Contact-impact between wheel and track surface after derailment in the vertical direction

When a wheel touches down on the track surface after derailment (Fig. 4), the impact force of the wheel on the track structure on the contact surface, $Q_{T Z}$, is given here as a function of the relative displacement between wheel and the track structure in the vertical direction, $\delta_{T Z}$, depending on material properties of the contact between wheel and the track structure as

$$
Q_{T Z}=Q_{T Z}\left(\delta_{T Z}\right)
$$

\section{INTERACTION BETWEEN THE CAR BODY AND RAILWAY STRUCTURE}

\subsection{Contact censor point $\mathrm{C}$ between the car body and railway structure}

In the pre- and post-derailments during a strong earthquake, the car body of the train may contact and impact on the railway structure. An efficient contact model to express the contactimpact behaviour between the car body and railway structure is given where a number, $n$, of contact censor points $\mathrm{C}_{i}(i=1, n)$ are given on the surface of the car body to detect the contact between the car body and railway structure effectively as shown in Fig. 5. When a censor point $\mathrm{C}$ contacts on the railway structure, the contact force is created between the car body and railway structure. Censor points $\mathrm{C}_{i}(i=1, n)$ needed are given depending on contact areas on the car body to express contact forces descretized (Fig. 5).

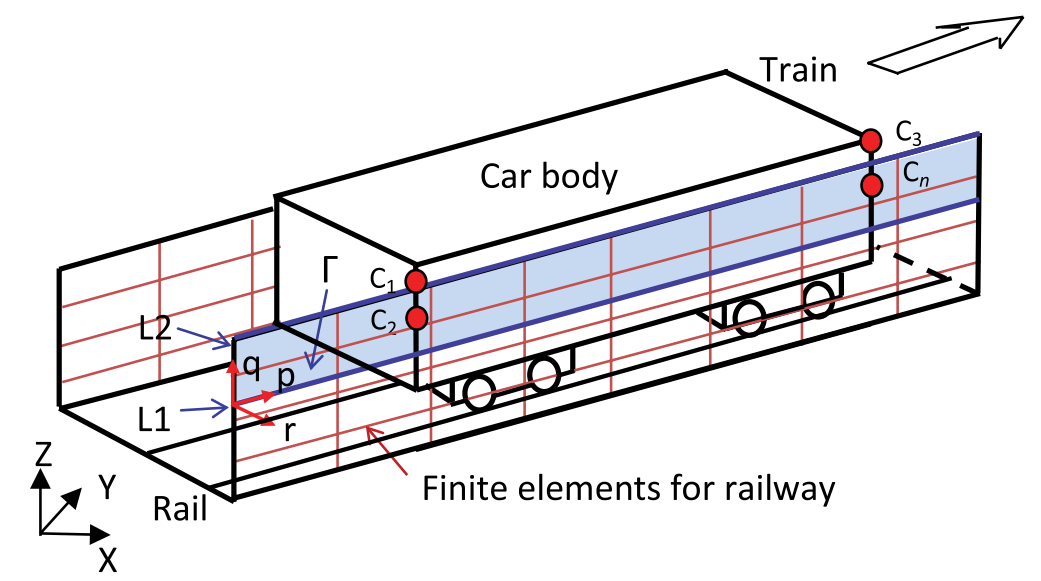

Figure 5: Contact between censor points $\mathrm{C}_{i}(i=1, n)$ on the car body and contact surface $\Gamma$ on the railway structure. 


\subsection{Definition of a contact surface $\Gamma$ on the railway structure}

A railway structure is modelled with various finite elements such as shell and solid elements. To make the contact calculation between the car body and railway structure effective, a contact surface $\Gamma$, that is a possible surface for censor points $\mathrm{C}_{i}(i=1, n)$ to contact on the railway structure, is defined on the finite element mesh of railway structure by using two lines of L1 and L2 in the rail direction as shown in a dark colour in Fig. 5. Lines L1 and L2 are the lower and upper bounds of the contact surface for the censor points to contact on the railway structure. The contact point $C$ on the car body can contact on the railway structure only if the point is within the surface $\Gamma$. The displacement of the surface, $\Gamma$, is approximated from nodal displacements of finite elements in the surface, $\Gamma$.

4.3 Contact displacement, $\delta_{C}$, and force, $F_{C}$, between the car body and railway structure at censor point $\mathrm{C}$

Local coordinates $p, q, r$ on the contact surface $\Gamma$ on the railway structure are defined as shown in Fig. 5, where, $p$ is the rail direction, $q$ is the vertical direction and $r$ is the normal direction on the surface $\Gamma$. The contact displacement between the car body and railway structure, $\delta_{C}$, at the point $\mathrm{C}$ in the normal direction is expressed as a function of displacements of the car body, $u_{C}$, and the contact surface, $u_{\Gamma}$, in the normal direction at the point $\mathrm{C}$ as

$$
\delta_{C}=\delta_{C}\left(u_{c}, u_{\Gamma}, \varepsilon_{\Gamma}\right)
$$

where, $\varepsilon_{\Gamma}$ is the irregularity in the normal direction on the contact surface $\Gamma$ of railway structure. The contact force, $F_{C}$, is obtained here as a nonlinear function of contact displacement, $\delta_{C}$, between the car body and railway structure at $\mathrm{C}$ as

$$
F_{C}=F_{C}\left(\delta_{C}\right)
$$

The relationship of the contact displacement and contact force between the car body and railway structure at point $\mathrm{C}$ is obtained from experiments or the finite element static contact analysis between the car body and railway structure. The contact force, $F_{C}$, is applied to the car body of the train at the point $\mathrm{C}$ and to the railway structure at the contact point on the contact surface $\Gamma$.

\section{NUMERICAL EXAMPLES}

The combined dynamic response of the train and railway structure during an earthquake is obtained by solving nonlinear equations of motions of the train and railway structure in eqns. (1) and (2) subjected to the interaction between wheel and rail before derailment, between wheel and the track structure after derailment and between the car body and railway structure during and after derailment as discussed in Sections 3 and 4. However, a modal reduction to displacement vectors of the train and railway structure is applied to solve the combined response of a large-scale railway system during an earthquake effectively [6]. Equations of motions of the train and railway structure are solved in modal coordinates for each time increment. However, since the equations are strongly nonlinear, iterative calculations are made during each time increment until they converge within a small tolerance specified.

The contact model between the train and railway structure presented here has been implemented in the simulation program DIASTARS [6] for dynamic interaction analysis of 
a Shinkansen train and railway structure including derailment and post-derailment during an earthquake.

5.1 Simulation of a Shinkansen car running on the railway structure with side walls attached during an earthquake

The simulation of a Shinkansen car running at a speed of $300 \mathrm{~km} / \mathrm{h}$ on the railway structure with side walls attached during a sinusoidal seismic wave with the frequency of $1 \mathrm{~Hz}$, the maximum amplitude of $3.8 \mathrm{~m} / \mathrm{s}^{2}$ and wave number of 5 given from the base in the transverse direction has been conducted (Fig. 6). Figure 7 shows the distance between the car body and side walls of the railway structure. The railway structure is assumed to be stiff and the side walls are modelled with stiff shell elements. The seismic wave of $1 \mathrm{~Hz}$ is a severe frequency for the car as it is close to the resonance frequency of the rolling motion of the car body, truck and wheel-set which leads to derailment easily. Four censor points $\mathrm{C}_{i}(i=1,4)$ at four corners of the car body are given at the height of the centre of gravity of the car body. The

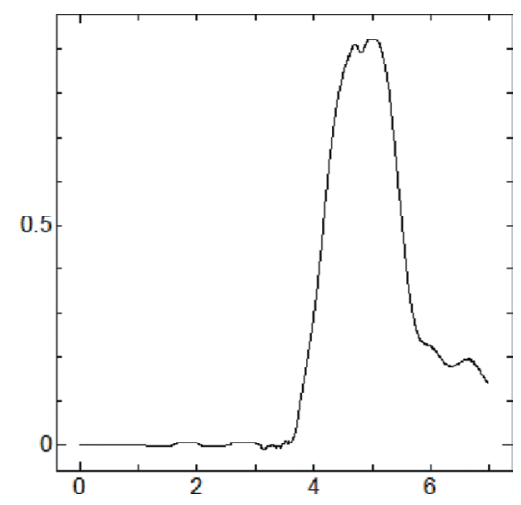

Figure 6: Contact displacement at $\mathrm{C}_{3}$.

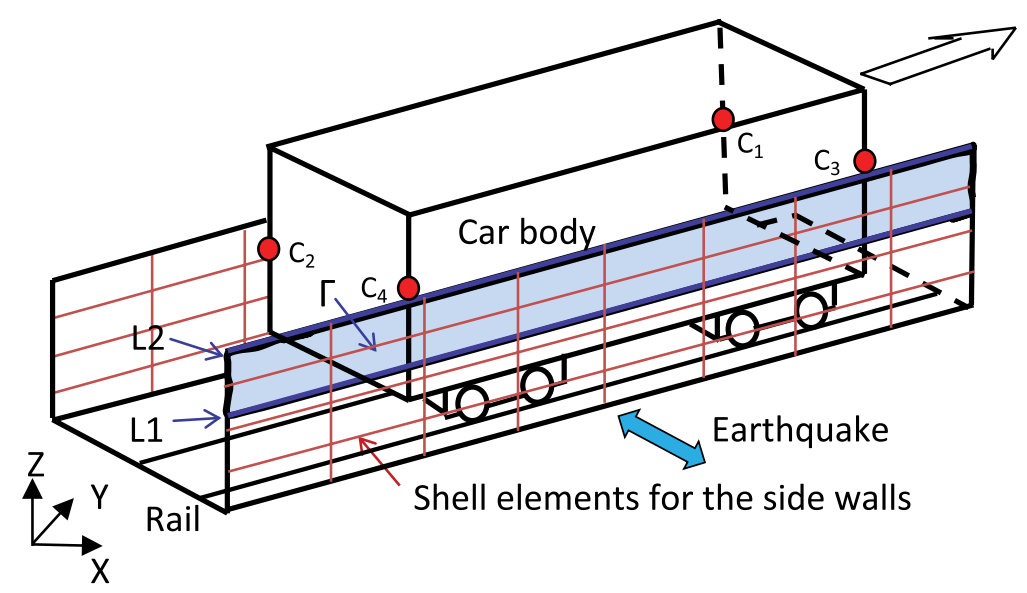

Figure 7: Contact between censor point $C_{i}(i=1,4)$ on the car body and contact surface $\Gamma$ on the railway structure. 


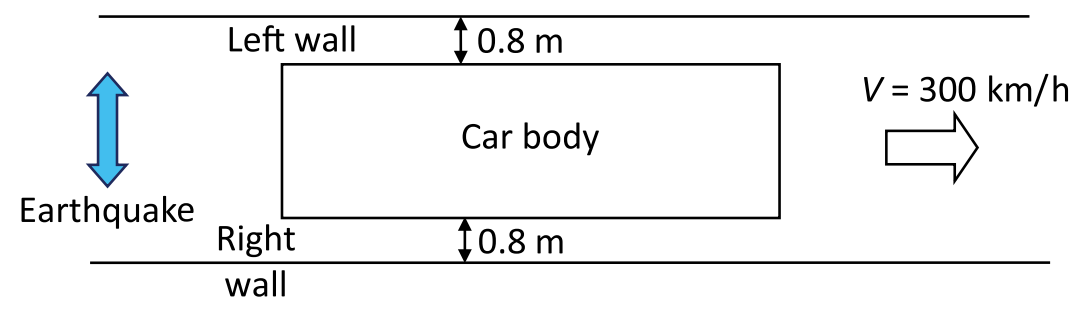

Figure 8: Car body and walls of railway structure.

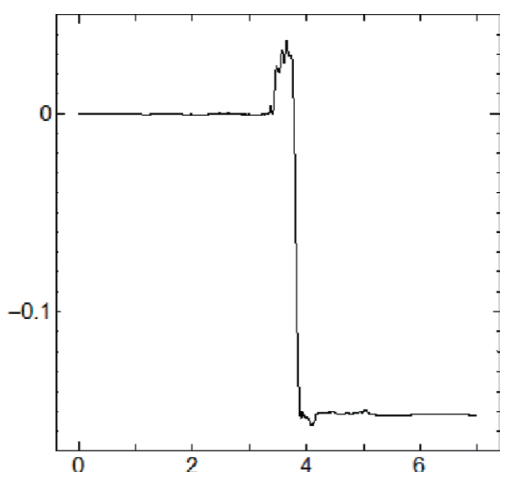

Figure 9: Vertical displacement of right wheel.

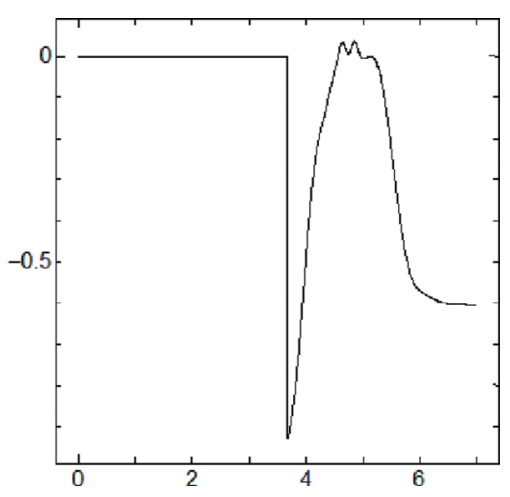

Figure 10: Relative displacement between right wheel and rail in the transverse direction.

contact force-displacement relationship per a half length of the car body given at points $\mathrm{C}_{i}$ $(i=1,4)$ was obtained from experiments when the car body contacted on the rigid wall [10]. Figure 8 shows the vertical displacement response of the right wheel at the 1 st wheel-set. It is shown that the wheel runs onto the rail due to the impact between the wheel and rail in the transverse and vertical directions, lifts off, derails and touches down on the track at the time around $t=3.66(\mathrm{~s})$. Figure 9 shows the relative displacement response between the right wheel and rail in the transverse direction, $d_{y}$, at the 1 st wheel-set. When $d_{y}$ exceeds $\mathrm{u}_{\mathrm{F}}(7 \mathrm{~cm}$ in this case; shown in Fig. 3(a)), the derailment to field side is initiated. Figure 10 shows the 


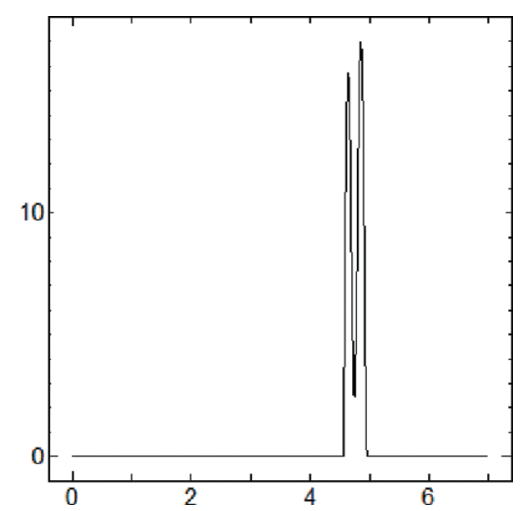

Figure 11: Contact force at $\mathrm{C}_{3}$.

contact displacement, $\delta_{C}$, at $\mathrm{C}_{3}$. When $\delta_{C}$ is positive, it shows that there is a contact between the car body and the wall at the time around $t=4.6$. Figure 11 shows the contact force at $\mathrm{C}_{3}$. The maximum contact force between the car body at $\mathrm{C}_{3}$ and the side wall of railway structure is shown to be about 16.9 tonf for a half-length of the car body.

5.2 Simulation of a Shinkansen car running on the railway structure with irregular side wall attached in the transverse direction during an earthquake

The simulation of a Shinkansen car running at a speed of $300 \mathrm{~km} / \mathrm{h}$ on the railway structure with an irregular side wall attached during a sinusoidal seismic wave with the frequency of $1 \mathrm{~Hz}$, the maximum amplitude of $3.8 \mathrm{~m} / \mathrm{s}^{2}$ and wave number of 5 given from the base in the transverse direction has been conducted. The railway structure is also assumed to be stiff and side walls of the railway structure are modelled with rigid shell elements. An irregularity is given on the right side wall in the transverse direction in the slope of 1/200 in the rail direction as shown in Fig. 12. It is expected that the body contacts and impacts on the side wall during the earthquake. Four censor points $\mathrm{Ci}(\mathrm{i}=1,4)$ at four corners of the car body are also given at the height of the centre of gravity of the car body as in the previous example (Fig. 6). The contact force-displacement relationship per a half length of the car body given between the points $C_{i}(i=1,4)$ and the rigid wall is same as in the previous example. Figure 13 shows the vertical displacement response of the left wheel at the $1 \mathrm{st}$ wheel-set. It is shown that the wheel derails and touches down on the track at the time around $t=3.66$. Figure 14 shows the relative displacement response between the left wheel and rail in the transverse direction, $d_{y}$, at the $1 \mathrm{st}$ wheel-set. When $d_{y}$ exceeds $u_{\mathrm{G}}(-7 \mathrm{~cm}$ in this case; shown in Fig. 3(b)), the derailment to the gauge side is initiated. Figure 15 shows the contact displacement, $\delta_{C}$, at $\mathrm{C}_{1}$. It is shown that the car body contacts on the right side wall at $\mathrm{C}_{3}$ at the time around $t=4.8$ and on the left side wall at $\mathrm{C}_{1}$ at the time around $t=6.1$. Figure 16 shows the contact force at $\mathrm{C}_{1}$. The maximum contact force between the car body at $\mathrm{C}_{1}$ and the left side wall is shown to be about 13.1 tonf. 


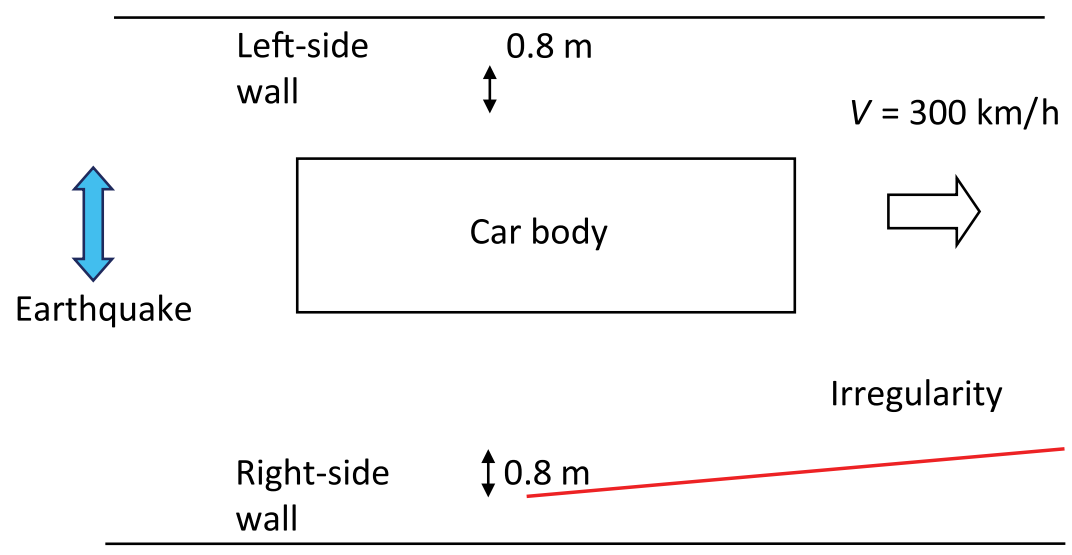

Figure 12: Car body and walls where an irregularity with the slope of $1 / 200$ is given in the transverse direction on the right side wall.

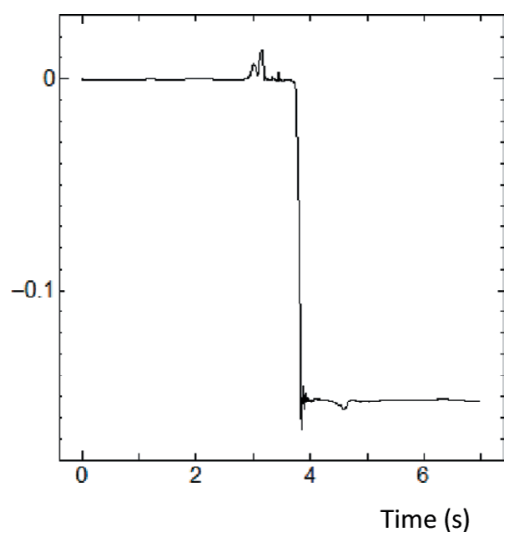

Figure 13: Vertical displacement of left wheel.

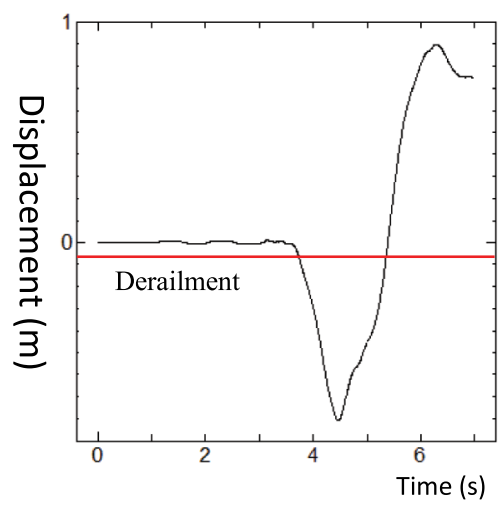

Figure 14: Relative displacement between left wheel and rail in the transverse direction. 


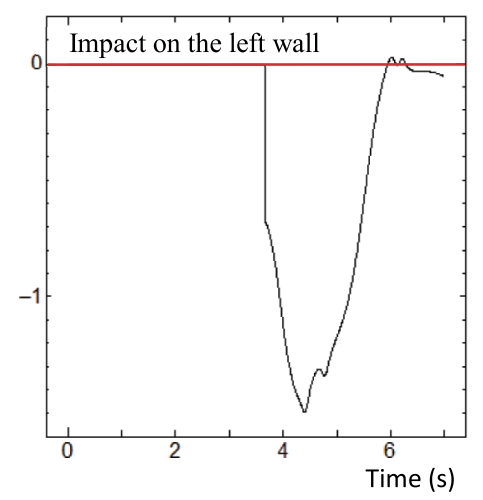

Figure15: Contact displacement at $\mathrm{C}_{1}$.

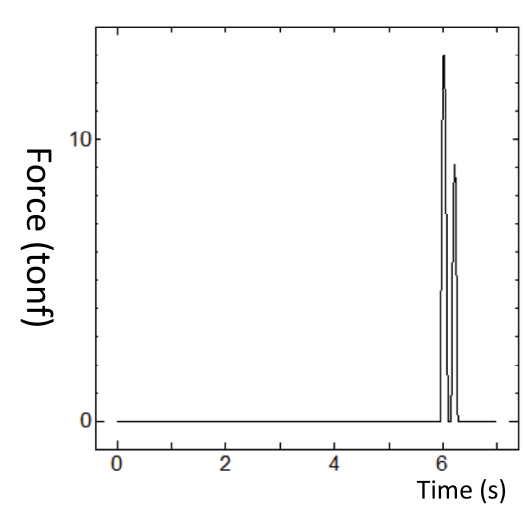

Figure 16: Contact force at $\mathrm{C}_{1}$.

\section{CONCLUSIONS}

A computational method to solve for the dynamic interaction of a high-speed train and railway structure including derailment and post-derailment during an earthquake was given. An efficient mechanical model to express contact-impact behaviours between wheel and rail before derailment and between wheel and the track structure after derailment was given to solve the interaction during an earthquake effectively. A contact model to express contactimpact behaviour between the car body and railway structure during and after derailment was presented, where the contact stiffness was described as a nonlinear function of the relative displacement.

The motion of the train with nonlinear springs and dampers was modelled in multibody dynamics. The railway structure was modelled with various finite elements. A modal reduction was applied to equations of motions of the train and railway structure to solve them effectively. Based on the contact model presented here, the simulation program has been developed to solve the dynamic interaction of a Shinkansen high-speed train and railway structure including derailment and post-derailment behaviours during an earthquake. 
Simulations of a Shinkansen car on the railway structure including radical dynamic behaviours of derailment and post derailment and also contact-impact of the car body on the side wall of railway structure during an earthquake were demonstrated.

The computational method developed here will be effective to design an earthquake-safe railway system since experiments of derailment and post-derailment of a high-speed train on the railway structure during an earthquake are not available.

\section{REFERENCES}

[1] Pombo, J., Ambrosio, J. \& Silva, M., A new wheel-rail contact model for railway dynamics. Vehicle System Dynamics, 45(2), pp. 165-189, 2007. DOI: 10.1080/00423110600996017.

[2] Ju, S.H., A simple finite element for nonlinear wheel/rail contact and separation simulations. Journal of Vibration and Control, 20(3), pp. 330-338, 2014. DOI: 10.1177/1077546312463753.

[3] Montenegro, P.A., Neves, S.G.M., Calcada, R., Tanabe, M. \& Sogabe, M., Wheel-rail contact formulation for analyzing the lateral train-structure dynamic interaction. Computers \& Structures, 152, pp. 200-214. 2015. DOI: 10.1016/j. compstruc.2015.01.004.

[4] Xiao, X., Ling, L. \& Jin, X., A study of the derailment mechanism of a high speed train due to an earthquake. Vehicle System Dynamics, 50(3), pp. 449-470, 2012. DOI: 10.1080/00423114.2011.597508.

[5] Sunami, H., Termichi, Y. \& Adachi, M., An analytical study of derailed vehicle motion from wheel-sleeper impacts, Journal of Railway Technology, 2(2), pp. 35-63, 2013. DOI: 10.4203/ijrt.2.2.2.

[6] Tanabe, M., Matsumoto, N., Wakui, H., Sogabe, M., Okuda, H. \& Tanabe, Y., A simple and efficient numerical method for dynamic interaction analysis of a high-speed train and railway structure during an earthquake. Journal of Computational and Nonlinear Dynamics, 3(041002), ASME, 2008. DOI: 10.1115/1.2960482.

[7] Tanabe, M., Matsumoto, N., Wakui, H. \& Sogabe, M., Simulation of a Shinkansen train on the railway structure during an earthquake. Japan Journal of Industrial and Applied Mathematics, 28, pp. 223-236, 2011. DOI: 10.1007/s13160-011-0022-4.

[8] Kalker, J.J., Three-Dimensional Elastic Bodies in Rolling Contact, Dordrecht, The Netherlands: Kluwer, Academic Publishers 1990.

[9] Japan Society of Mechanical Engineers, Dynamics of Railway Vehicle, Train Research Company, 1994 (in Japanese). ISBN 4-88548-074-4.

[10] Okino, T. \& Ujita, Y., Evaluation of car body strength against loads from the side. RTRI Report, 25(8), pp. 23-28, Railway Technical Research Institute, 2011 (in Japanese). 